\title{
ESTÁNDAR INTERAMERICANO DE LA DEBIDA DILIGENCIA: APLICACIÓN POR LAS ALTAS CORTES COLOMBIANAS EN LOS CASOS DE DELITOS DE VIOLENCIA SEXUAL CONTRA MUJERES EN EL CONFLICTO ARMADO
}

Inter-American Standard of Due Diligence: Application for Colombian High Courts in Cases of Crimes Sexual Violence against Women during the Armed Conflict ${ }^{1}$

Fecha de Recepción: Noviembre 4 de 2013

Fecha de Aceptación: Noviembre 11 de 2013

\author{
Yaneth Carolina Álvarez López ${ }^{2}$ \\ Nina Ferrer Araújo ${ }^{3}$ \\ Yucelis Garrido Ochoa ${ }^{4}$
}

SUMARIO: 1. Introducción, metodología, justificación, avances, resultados y discusión; 2. La situación de las mujeres colombianas en el marco del conflicto armado; 3. Debida diligencia en la prevención de actos

de violencia sexual contra mujeres; 4 . Debida diligencia en la atención y asistencia especializada a las mujeres, niñas, adolescentes y adultas mayores sobrevivientes a la violencia sexual perpetrada por actores armados; 5. Deberes mínimos de debida diligencia del estado en la investigación, juicio y sanción de actos de violencia sexual en contra de mujeres, niñas, adolescentes y adultas mayores perpetradas por actores armados. 6. El derecho de las mujeres víctimas de violencia sexual a la igualdad y el deber correlativo de los operadores de las normas, incluidos los defensores, de adoptar medidas para eliminar y prevenir la discriminación; 7. Conclusiones; 8. Referencias bibliográficas.

\footnotetext{
${ }^{1}$ Este texto es producto de la fase Exploratoria del Proyecto de Investigación: “El estándar de Debida Diligencia en los Procesos Judicial por violencia sexual en mujeres víctimas de desplazamiento forzado en la ciudad de Cartagena, que ha sido presentado a la Convocatoria de Joven Investigador de la Fundación Universitaria Tecnológico Comfenalco, que se adelanta desde el 16 de febrero de 2015, que cuenta con la colaboración para la consecución de los casos de estudios de la Organización LIMPAL COLOMBIA.

${ }^{2}$ Estudiante del Programa de Derecho de la Fundación Universitaria Tecnológico Comfenalco en Convenio con la Universidad de Medellín. Joven investigadora del Programa de Derecho, vinculada al semillero Humana luris, adscrito al Grupo de Investigaciones Sociales y Jurídicas, correo electrónico: yanethalvarezlopez@gmail.com
} 


\section{COMO SE CITA ESTE ARTÍCULO (APA 6)}

Álvarez López, Y. C.; Ferrer Araújo, N.; Garrido Ochoa, Y. (2014) Estándar interamericano de la debida diligencia: aplicación por las altas cortes colombianas en los casos de delitos de violencia sexual contra mujeres en el conflicto armado. (Y. Carrillo De la rosa, Ed.) Revista Jurídica Mario Alario D'Filippo, VI (11), pág. $37-49$

\section{RESUMEN}

El texto que se presenta hace un rastreo de la jurisprudencia de la Corte Constitucional Colombiana, el Consejo de Estado y la Corte Suprema de Justicia, en la que los Altos Tribunales han aplicado los estándares interamericanos de debida diligencia como fundamento para desatar controversias en las que se ven envueltos derechos humanos de mujeres víctimas de violencia sexual. Lo anterior con una doble finalidad: por un lado, observar la manera como las Altas Cortes han aplicado los estándares; por otro, permitir el análisis de cómo Tribunales de otros niveles y operadores jurisdiccionales han omitido las demandas del estándar.

\section{PALABRAS CLAVE}

Estándar de debida diligencia, derechos de las mujeres, violencia sexual en el conflicto armado, aplicación doméstica del corpus iuris interamericano.

\section{ABSTRACT}

The text presented makes a tracking about jurisprudence of the Colombian Constitutional Court, the State Council and the Supreme Court, in which the High Courts have applied the inter-American standards of due diligence as a basis to trigger disputes in which involved human rights of women victims of sexual violence. These two purposes: first, to observe how the High Courts have applied the standards; on the other, allow analysis of how courts of other jurisdictional levels and operators have failed standard demands.

\section{KEYWORDS}

Standard of due diligence, women's rights, sexual violence in armed conflict, domestic application of corpus juris Inter.

\footnotetext{
${ }^{3}$ Abogada, especialista en Derecho Comercial, Candidata a Magister en Género Sociedad y Política de la facultad Latinoamericana de ciencias sociales - FLACSO. Docente de la Fundación Universitaria tecnológico Comfenalco, adscrita al Grupo de Investigaciones Sociales y Jurídicas del Programa de Derecho. Coordinadora del Semillero de Investigación "Humana luris". Perteneciente a la Junta directiva de LIMPAL_COLOMBIA.CorreoE: nferrer@tecnologicocomfenalco.edu.coyalmash7@hotmail.com.

${ }^{4}$ YUCELIS GARRIDO OCHOA, Abogada de la Universidad de Cartagena, Candidata a Magister en Derecho, integrante del grupo de Investigaciones Sociales y Jurídicas de la Fundación Universitaria Tecnológico Comfenalco, en convenio con la Universidad de Medellín, Docente de Sociología Jurídica de la misma Universidad. Joven Investigadora de Colciencias, beneficiada con la beca Pasantía del Programa.Correo Electrónico.ygarrido@tecnologicocomfenalco.edu.co
} 


\section{INTRODUCCIÓN}

En reiterados documentos, informes, sentencias del Sistema Interamericano de Derechos Humanos se destaca el deber estatal de debida diligencia y su alcance para la prevención, investigación y sanción de crímenes basados en el género, y el significado del derecho de acceso a la justicia de las víctimas de violencia. Este deber deviene de la interpretación del alcance del Art. 1.1 de la Convención Americana de Derechos Humanos en concordancia con el Artículo 7 de la Convención de Belem Do Pará. Esta obligación estatal exige, en general, organizar el aparato estatal para asegurar el libre y pleno ejercicio de los derechos humanos de toda persona e implica el deber de prevenir, investigar, sancionar y reparar adecuadamente todas sus violaciones.

El Estado Colombiano ha suscrito tanto la Convención Interamericana de Derechos Humanos como la Convención de Belem Do Pará, además ha aceptado la Competencia de la Corte Interamericana de Derechos Humanos y de la Comisión para el conocimiento de casos contenciosos por posibles violaciones de Derechos Humanos en los que el Estado sea demandado. De igual forma a partir del Artículo 93 de la Constitución Política Colombiana, que establece el Bloque de Constitucionalidad, tanto las normas internacionales de derechos humanos como las sentencias emitidas por la Corte en ejercicio de sus funciones contenciosas hacen parte integrante de la Constitución como norma de normas, es decir que los estándares fijados sin lugar a dudas son de obligatorio cumplimiento; no obstante son populares las demandas de la ciudadanía civil por falta de esta implementación en la práctica diarias de nuestros tribunales y organismos jurisdiccionales, asunto que se pretende abordar en este recorrido por la jurisprudencia ante las Altas Cortes.

\section{METOdOLOGÍA}

Este texto hace parte de una fase previa de una investigación socio jurídica, de enfoque cualitativo y de tipo estudio de caso; no obstante lo que se recoge en este documento da cuenta de una fase bibliográfica, basada específicamente en el análisis documental.

\section{JUSTIFICACIÓN}

La pregunta que dio origen a esta investigación fue ¿cuál es el grado de cumplimiento del estándar de debida diligencia en los casos de estudio seleccionados de procesos judiciales por violencia sexual ejercida contra las mujeres en condición de desplazamiento forzado ubicadas en Cartagena como ciudad receptora?, que nace de la percepción de innumerables violaciones de derechos humanos de las mujeres colombianas víctimas de violencia sexual, al respecto desde el Auto 092 de 2008, la Corte Constitucional Colombiana ha reconocido las especiales condiciones de vulneración de las mujeres en contextos de conflictos y en especial de las mujeres colombianas, demostrando que los cuerpos de las mujeres son entendidos y tratados como territorios de guerra. Este estudio por su carácter evaluativo permite la verificación del cumplimiento del deber estatal colombiano en unos casos precisos, coadyuvando a la divulgación de los resultados ante organismos nacionales de defensa de los Derechos Humanos, a partir del Convenio con la Organización LIMPAL COLOMBIA, para fortalecer el acceso de las mujeres a los espacios de justifica efectiva. 
Además el proyecto alimenta las dos líneas de investigación establecidas por el Grupo de Investigaciones Sociales y Jurídicas del Programa de Derecho de la Fundación Universitaria Tecnológico Comfenalco, esto es la línea de "acceso a la justicia" y la de "Derecho y sociedad" en su sublínea de "Género y Derecho", así como el trabajo del semillero de Investigación "Humana luris".

\section{AVANCES, RESULTADOS Y DISCUSIÓN}

\section{LA SITUACIÓN DE LAS MUJERES COLOMBIANAS EN EL MARCO DEL CONFLICTO ARMADO}

En reiterados documentos, informes, sentencias del Sistema Interamericano de Derechos Humanos (en adelante SIDH) se destaca el deber estatal de debida diligencia y su alcance para la prevención, investigación y sanción de crímenes basados en el género, y el significado del derecho de acceso a la justicia de las víctimas de violencia. Este deber deviene de la interpretación del alcance del Art. 1.1 de la CADH.

La obligación estatal exige, en general, organizar el aparato estatal para asegurar el libre y pleno ejercicio de los derechos humanos de toda persona e implica el deber de prevenir, investigar, sancionar y reparar adecuadamente todas sus violaciones. Ahora bien, en los casos de violencia contra las mujeres este deber debe ser iluminado por el enfoque de género que surge de la norma más específica: la Convención de Belém do Pará. Así, la Corte habla no solo de las obligaciones genéricas contenidas en la CADH, sino también de unas "obligaciones reforzadas" de prevención e investigación, de conformidad con el estándar de "debida diligencia" establecido en el Art. 7 (b) de la Convención contra la violencia hacia las mujeres: "En particular, deben contar con un adecuado marco jurídico de protección, con una aplicación efectiva del mismo y con políticas de prevención y prácticas que permitan actuar de una manera eficaz ante las denuncias. La estrategia de prevención debe ser integral, es decir, debe prevenir los factores de riesgo y a la vez fortalecer las instituciones para que puedan proporcionar una respuesta efectiva a los casos de violencia contra la mujer. Asimismo, los Estados deben adoptar medidas preventivas en casos específicos en los que es evidente que determinadas mujeres y niñas pueden ser víctimas de violencia". (Corte Interamericana de derechos humanos caso campo algodonero 2009, párr. 258)

Con ocasión del conflicto las mujeres sufren especial vulneración de sus derechos, especialmente de los sexuales, en vista que de manera tradicional su cuerpo ha sido considerado campo y botín de guerra. En el caso colombiano tal como lo reconoció la Corte Constitucional en la Sentencia C-025 de 2004 y en el Auto 092 del 2008 de seguimiento a la misma, se presenta una situación similar, en la que la violencia sexual es una práctica sistemática y reiterada ejercida por todos los actores del conflicto armado como el estado colombiano. En esta providencia los accionantes (las víctimas del desplazamiento forzoso) solicitan ayuda de entidades que les puedan proporcionar apoyo y seguridad con base en un sistema de amparo a sus derechos fundamentales inherentes. Por ello entraremos analizar que ha manifestado la corte al respecto.

Así como en auto de seguimiento 009/15 al observar que la situación de las mujeres, jóvenes, niñas y adultas mayores desplazadas por el conflicto armado constituye una de las manifestaciones más críticas del estado de cosas inconstitucional declarado en la sentencia T-025 de 2004, la Corte 
Constitucional emitió el Auto 092 de 2008 con fundamento en su condición de sujetos de especial protección constitucional.

En este auto se constaron: (i) los riesgos con ocasión a la condición género a los cuales se encuentran expuestas las mujeres, jóvenes, niñas y adultas mayores en condición de desplazamiento, entre los cuales identificó el riesgo de violencia sexual, como una situación fáctica alarmante por ser lesiva de los derechos humanos y del Derecho Internacional Humanitario que ampara a las mujeres como víctimas del conflicto; (ii) la situación sistemática, extendida y masiva de la vulneración de la integralidad de sus derechos a lo largo del territorio nacional; (iii) la respuesta estatal manifiestamente insuficiente frente a esta situación y frente al cumplimiento de sus deberes constitucionales; y (iv) la existencia de elementos en la política pública de atención al desplazamiento forzado que dejan vacíos críticos respecto de la situación de total desamparo de las mujeres desplazadas ante las autoridades obligadas a protegerlas.

Igualmente la Corte señaló que las mujeres desplazadas están mayormente expuestas al riesgo de violencia y abuso sexuales, así como a la prostitución forzada, la esclavitud sexual y la trata de personas con fines de explotación sexual. En particular, se llamó la atención sobre el surgimiento de dinámicas sexualmente violentas durante la etapa de emergencia del desplazamiento.

De acuerdo con lo observado por esta Sala, uno de los factores que contribuye significativamente a que la violencia sexual contra mujeres y niñas en el marco del conflicto armado interno y el desplazamiento forzado siga siendo invisible y, en consecuencia, subregistrada y deficientemente atendida y sancionada, es la casi total imposibilidad de hecho que enfrentan las mujeres para dar a conocer a terceros entre estos al personal sanitario y a las autoridades competentes los hechos de victimización sexual de manera expedita.

Así mismo la Corte Constitucional establece que las obligaciones constitucionales derivadas del deber de debida diligencia en la prevención, atención protección y acceso a la justicia a favor de las mujeres sobrevivientes de la violencia sexual perpetrada por actores armados y que le asisten al Estado colombiano de cara son: (i) prevenir la violencia la sexual en el marco del conflicto armado interno y el desplazamiento forzado por la violencia, (ii) atender y proteger a sus víctimas, y (iii) garantizar la investigación, el enjuiciamiento y la sanción de los responsables.

Este marco jurídico será delineado a la luz del deber de diligencia debida, consagrado en la "Convención sobre la Eliminación de todas las Formas de Discriminación contra la Mujer CEDAW" (Ratificada por Colombia el 19 de enero de 1982) y en la Convención Interamericana para Prevenir, Sancionar y Erradicar la Violencia contra las Mujeres Convención de Belem do Pará. Primero, por cuanto los citados instrumentos internacionales del Sistema Universal de los Derechos Humanos y del Sistema Interamericano de los Derechos Humanos, respectivamente, hacen parte del ordenamiento constitucional interno en virtud del Artículo 93 de la Carta Política y la figura del bloque de constitucionalidad en sentido estricto los principios allí contenidos sobre la no discriminación y la erradicación de la violencia contra la mujer, no son susceptibles de suspensión en estados de excepción, y en este orden de ideas, deben ser acatados de manera íntegra por el Estado colombiano en todo tiempo y lugar. 
En segundo término, por cuanto sus disposiciones contienen un conjunto normativo plenamente compatible con otros tratados internacionales de obligatorio cumplimiento para Colombia, tales como: el "Pacto Internacional de los Derechos Civiles y Políticos" (Ratificado por Colombia el 29 de octubre de 1969.), el "Pacto Internacional de los Derechos Económicos, Sociales y Culturales" (Ratificado por Colombia el 29 de octubre de 1969.), la "Convención sobre los Derechos del Niño" (Ratificada por Colombia el 19 de enero de 1982.), la "Convención Americana sobre Derechos Humanos" (Ratificada por Colombia el 15 de noviembre de 1996.), la "Convención sobre los Derechos de las Personas con Discapacidad" (Ratificada por Colombia el 10 de mayo de 2011.), entre otros instrumentos, que redoblan su fuerza vinculante.

En tercer lugar, por cuanto "la CEDAW y la Convención Belem do Pará contienen un conjunto de directrices en materia de derechos específicos de las mujeres, medios de protección y obligaciones concretas de los Estados, que pretenden contribuir a la corrección, mediante medidas positivas, de la situación de discriminación histórica a que han estado sometidas las mujeres en razón del género, que las ha situado en una posición de desventaja social, económica, política y cultural, y respecto de la cual una de las manifestaciones más lesivas se expresa en las distintas formas de violencia en su contra, entre ellas, la violencia sexual. De acuerdo con ello, los estándares internacionales de la Convenciones CEDAW y Belem Do Pará han sido aplicados de manera reiterada por la jurisprudencia de esta Corte" (Corte constitucional, Sentencia T-496 de 2008) y de otros altos tribunales, de manera que es claro que sus disposiciones constituyen pautas de interpretación de obligatorio cumplimiento tanto para los funcionarios judiciales como para las entidades públicas del Ejecutivo, Legislativo y los entes de control del Estado, encargadas de velar por el cumplimiento de los derechos humanos de las mujeres y, en particular, de las mujeres víctimas del conflicto armado y el desplazamiento forzado por la violencia.

\section{DEBIDA DILIGENCIA EN LA PREVENCIÓN DE ACTOS DE VIOLENCIA SEXUAL CONTRA MUJERES}

La debida diligencia en la prevención de la violencia sexual por parte del Estado, parte de su compromiso internacional de adoptar todas las medidas necesarias -administrativas, legislativas, judiciales, financieras y fiscales- para la adopción, implementación y seguimiento de políticas públicas efectivas y adecuadas tendientes a eliminar toda manifestación de violencia y discriminación en razón del género; teniendo en cuenta que, como fuera consignado en la Declaración de Beijing, y en la misma línea, por la Comisión Interamericana de Derechos Humanos: "la violencia contra la mujer es una manifestación de las relaciones de poder históricamente desiguales entre mujeres y hombres, que han conducido a la dominación de la mujer por el hombre, a la discriminación contra la mujer y a la interposición de obstáculos contra su pleno desarrollo" (Declaración y Plataforma de Acción de Beijing. Ibíd. Párr. 118; Comisión Interamericana de Derechos Humanos 20 de enero de 2007. Párr. 67).

Para tales efectos, "las medidas deben ser integrales, en el sentido de que, por un lado "[...] deben prevenir los factores de riesgo" y a la vez "[...] fortalecer las instituciones para que puedan proporcionar una respuesta efectiva a los casos de violencia contra la mujer". (Corte Interamericana de Derechos Humanos, Caso Campo Algodonero Sentencia del 16 de noviembre de 
2009. Párr. 258). De este modo, la Convención Belem do Pará señala que "el Estado es responsable de adoptar de manera progresiva "por todos los medios apropiados y sin dilaciones, políticas orientadas a prevenir, sancionar y erradicar dicha violencia [...]" (Convención de Belem do Pará, 1994). Por medios apropiados para desarrollar políticas de prevención de la violencia de género se entienden: “(i) la transformación de la cultura institucional estatal frente a la violencia y la discriminación contra la mujer; (ii) la transformación de la cultura de la sociedad en general; (iii) la adopción de mecanismos administrativos y legislativos que procuren el derecho de las mujeres a vivir una vida libre de violencia y discriminación; y (iv) la aplicación de la garantía de verdad, justicia y reparación a las sobrevivientesde violencia sexual, en tanto medida preventiva por excelencia y la "primera línea de defensa" contra este tipo de violencia"5. (Corte Constitucional, Auto 092 del 2008)

Sumado a lo anterior, tanto la Corte Interamericana de Derechos Humanos como la Corte Europea de Derechos Humanos, han señalado que se configura un desconocimiento del deber de debida diligencia en materia de prevención de los actos de violencia cuando los Estados, teniendo conocimiento de la posibilidad de vulneración de derechos humanos o, si por mandatos constitucionales debía tener este conocimiento, no adopta medidas concretas para evitar la concreción del acto o los actos violentos. Esta subregla ha sido aplicada en casos de violencia doméstica, como en situaciones de violencia generalizada en los que se han cometidos actos de violencia contra mujeres.

Ahora bien, respecto de los niños, niñas y adolescentes, el deber de debida diligencia en la prevención de actos de violencia, adquiere alcances específicos y reforzados, habida cuenta de la existencia de cláusulas convencionales, e incluso constitucionales, que expresamente exigen al Estado garantizar "vidas libres de violencia".

\section{DEBIDA DILIGENCIA EN LA ATENCIÓN Y ASISTENCIA ESPECIALIZADA A LAS MUJERES, NIÑAS, ADOLESCENTES Y ADULTAS MAYORES SOBREVIVIENTES A LA VIOLENCIA SEXUAL PERPETRADA POR ACTORES ARMADOS}

Las obligaciones constitucionales que le asisten al Estado, son claras en señalar que las mujeres víctimas de cualquier acto de violencia que vulnere sus derechos humanos, incluidas las sobrevivientes de violencia sexual, deben ser atendidas de forma inmediata, integral, especializada, con enfoque diferencial, de forma gratuita y durante el tiempo necesario para superar las afectaciones físicas y sicológicas derivadas de las agresiones, y que la cobertura de esta atención debe incluir a la familia de la víctima. De acuerdo con la Sentencia C-776 de 2010 emitida por la Corte Constitucional, las mujeres víctimas de violencia no solo son destinatarias de valoración médica, tratamientos, procedimientos quirúrgicos o medicación, sino también de alojamiento y alimentación, durante el período que ellas requieran, bajo el entendido de que estos

\footnotetext{
${ }^{5}$ Las obligaciones específicas derivadas del principio de debida diligencia sobre este último punto, serán ampliadas en el aparte 3 de la presente sección, titulado: Deberes mínimos de debida diligencia del Estado en la investigación, juicio y sanción de actos de violencia sexual en contra de mujeres, niñas, adolescentes y adultas mayores en el marco del conflicto armado interno y el desplazamiento forzado.
} 
dos últimos componentes hacen parte de su derecho fundamental a la atención integral en salud.

Del mismo modo, el Comité de la CEDAW recomienda a los Estados:

“(i) establecer o apoyar “(...) servicios destinados a las víctimas de violencia en el hogar, violaciones, violencia sexual y otras formas de violencia contra la mujer, entre ellos refugios, el empleo de trabajadores sanitarios especialmente capacitados, rehabilitación y asesoramiento"; (ii) adoptar "medidas de protección, entre ellas refugios, asesoramiento, rehabilitación y servicios de apoyo para las mujeres que son víctimas de violencia o que se encuentren en peligro de serlo" y (iii) proporcionar "protección y asistencia a las mujeres y las niñas desplazadas internas y refugiadas, en particular: amparándolas frente a la violencia de género y el matrimonio forzado y en la infancia; velando por su acceso a los servicios y a la atención de la salud en condiciones de igualdad y por su participación plena en la distribución de suministros, así como en el desarrollo y la aplicación de programas de asistencia que tengan en cuenta sus necesidades específicas". (Comité para la Eliminación de la Discriminación contra la Mujer (Comité CEDAW). Recomendación General No. 19 de 1992)

En la Sentencia T- 045 de 2010, la Corte Constitucional Colombiana ordenó al Ministerio de Protección Social, hoy Ministerio de Salud, la inclusión de la atención psicosocial permanente para atención a las víctimas del conflicto armado, con cobertura para la mujer víctima de violencia sexual, su núcleo familiar y su comunidad, hasta tanto la mujer, su núcleo familiar y su comunidad hayan restablecido su salud mental. Igualmente, el acompañamiento psicológico debe garantizarse durante la participación de las mujeres en el proceso judicial, desde el primer contacto con las entidades públicas encargadas de recibir la declaración o la denuncia de los hechos, hasta la culminación del procedimiento, a fin de que la mujer no sufra afectaciones adicionales derivadas de la presión del procedimiento judicial.

Así las cosas, "la víctima debe contar con un equipo interdisciplinario jurídico y psicosocial que acompañe y respalde su intervención, desde la denuncia hasta la culminación del proceso judicial, con el propósito de garantizarle las mejores condiciones posibles" ${ }^{\prime}$. (Corte Interamericana de Derechos Humanos Caso Rosendo Cantú contra México, Sentencia del 31 de agosto de 2010. Párr. 189)

De otra parte, varias normas del sistema jurídico nacional han incorporado algunas de las exigencias internacionales sobre la atención a las víctimas de actos de violencia sexual. De un lado, mediante la Ley 360 de 1997 que establece el derecho de las víctimas de violencia sexual, a tener acceso gratuito a exámenes y tratamientos, tanto para la prevención de enfermedades de transmisión sexual incluido el VIH/SIDA, como para la atención física y emocional. Y de otro, mediante el Artículo 8) literal c) de la Ley 1257 de 2008 que establece el deber del Estado de garantizar a la víctima información clara, completa, veraz y oportuna en relación con la salud sexual y reproductiva, así como recibir asistencia médica, psicológica, psiquiátrica y forense especializada e integral, en los términos y condiciones establecidos en el ordenamiento jurídico para ellas y sus hijos e hijas.

\footnotetext{
${ }^{6}$ Al respecto, la Corte Interamericana de Derechos Humanos expresó lo siguiente: “[...] el apoyo a una víctima de violencia sexual es fundamental desde el inicio de la investigación para brindar seguridad y un marco adecuado para referirse a los hechos sufridos y facilitar su participación, de la mejor manera y con el mayor de los cuidados, en las diligencias de la investigación". Ver al respecto: CortelDH. Caso Rosendo Cantú contra México. Sentencia del 31 de agosto de 2010. Párr. 189. Ver también: Corte IDH. Caso Fernández Ortega y otros vs. México, Excepciones Preliminares, Fondo, Reparaciones y Costas. Sentencia del 30 de agosto de 2010 Serie C. No. 215; CIDH. Acceso a la Justicia para las Mujeres Víctimas de Violencia Sexual en Mesoamérica. Ibíd. Párr. 93.
} 
En particular, la Sala hace énfasis en el derecho de las víctimas de violencia sexual a restablecer de manera plena su salud sexual y reproductiva, y en la obligación del Estado de proveer asistencia médica completa, gratuita y permanente. El Estado debe brindar a las sobrevivientes de violencia sexual los recursos integrales en salud, tales como: exámenes médicos completos y tratamientos de calidad, que por un lado, diagnostiquen de manera completa las afectaciones en la salud de las sobrevivientes, y por otro, ordenen las medidas y tratamientos necesarios para superar estas afectaciones.

Por otro lado, de acuerdo con las agudas circunstancias de vulnerabilidad de las mujeres agredidas sexualmente en el marco del conflicto armado interno y el desplazamiento forzado, las ayudas derivadas del hecho del desplazamiento forzado deben ser asignadas de forma inmediata. De tal modo, que las entidades deben actuar con la debida diligencia al reconocer y entregar las ayudas de emergencia, tendientes a la estabilización socioeconómica de las mujeres víctimas.

\section{DEBERES MÍNIMOS DE DEBIDA DILIGENCIA DEL ESTADO EN LA INVESTIGACIÓN, JUICIO Y SANCIÓN DE ACTOS DE VIOLENCIA SEXUAL EN CONTRA DE MUJERES, NIÑAS, ADOLESCENTES Y ADULTAS MAYORES PERPETRADAS POR ACTORES ARMADOS}

En las Resoluciones 1888 de 2009 y la Resolución 1960 de 2010, ambas referidas a la violencia sexual en contra de mujeres y niños en los conflictos armados, el Consejo de Seguridad de las Naciones Unidas hace un llamado enfático a los Estados a poner fin a la impunidad por la comisión de crímenes sexuales. De la misma manera, en la Recomendación General 30, sobre las Mujeres en la Prevención de Conflictos y en Situaciones de Conflicto y Posteriores a Conflictos, el Comité de la CEDAW establece la obligación específica de los Estados de investigar, enjuiciar y sancionar la violencia de género que se produce como consecuencia del ciclo de desplazamiento.

La inobservancia del deber de debida diligencia en las investigaciones, juicios y sanciones penales contra los responsables de violaciones a los Derechos Humanos y al Derecho Internacional de Humanitario, propicia la perpetuidad de las condiciones sociales que dan lugar a la vulneración de los derechos fundamentales de las sobrevivientes de estos crímenes sexuales, en tanto la inacción o actuación deficiente del Estado en la vinculación de los responsables a un proceso penal y la aplicación de las sanciones correspondientes, refuerza los patrones de discriminación y violencia, al enviarse un mensaje a la sociedad y a los agresores en el sentido que la violencia contra las mujeres es tolerada, y que su comisión no apareja consecuencias jurídico-penales ni rechazo institucional.

Por otra parte, el deber de debida diligencia es a su vez consistente con la obligación internacional de los Estados de proveer un recurso judicial efectivo, que permita a los ciudadanos y ciudadanas la posibilidad real de solicitar ante las autoridades competentes: (i) la declaración de que un derecho está siendo vulnerado, (ii) el cese de la vulneración y (iii) la reparación adecuada por los daños causados.

El consejo de estado mediante Expediente 40411 (Consejo de Estado sala de lo contencioso Administrativo sección tercera-subsección B Bogotá, D. C, (09) de octubre (2014). al referirse al Caso González Campo Algodonero vs. México manifiesta:

"la construcción del estándar del deber de debida diligencia reforzado por actos violentos de actores no estatales. Advierte que en 2009, la Corte Interamericana de Derechos Humanos, en el caso conocido como "Campo Algodonero" inauguró una línea jurisprudencial en el sistema interamericano de derechos humanos sobre violencia contra las mujeres a partir del deber de debida diligencia basado en el género, es decir, 
examinó la responsabilidad estatal por parte de terceros a la luz de las bases sentadas por la Convención de Belém do Pará CBDP"7. (Artículo 10 de la Convención de Belén Do Para)

Los hechos ocurrieron en la ciudad de Juárez donde se constató el aumento exponencial de la tasa de homicidios de mujeres, pese a ello, las autoridades estatales no investigaron seriamente y se limitaron a elaborar los registros de algunas mujeres desaparecidas. Posteriormente, se encontraron los cuerpos de las víctimas, quienes presentaban signos de violencia sexual y el alto tribunal concluyó que estuvieron privadas de su libertad antes de su muerte.

La Corte adujo que la violencia ejercida en contra de las mujeres víctimas por parte de particulares fue cometida por "razones de género" y, para llegar a esta conclusión, hizo uso, como lo ha hecho en otras oportunidades, del estándar de protección convencional de "debida diligencia".

En este fallo, la Corte Interamericana atribuyó responsabilidad internacional del Estado por hechos violentos de terceros tomando como base la teoría del riesgo previsible y cognoscible. En consecuencia, el tribunal construyó una "estructura de imputación" de la responsabilidad del Estado por hechos de "actores no estatales" a partir de un deber de debida diligencia en la protección de la violencia de género frente a riesgos previsibles y cognoscibles, y lo aplicó a prácticas recurrentes de violencia contra las mujeres. En suma, esta sentencia estructura la responsabilidad estatal por hechos violentos de terceros en la doctrina del riesgo y exige que se reúnan dos elementos: i) que el Estado incumpla con el deber de debida diligencia en la protección de la violencia de género frente a actos violentos de actores no estatales; y ii) que se trate de riesgos previsibles y cognoscibles para el Estado.

En el año 2014 La Sección Tercera del Consejo de Estado condenó a la Nación por el acceso carnal violento y el secuestro de una mujer en Tame (Arauca) (Consejo de Estado, Sección Tercera, Sentencia 07001233100020020022801 (29033), oct. 9/14), por parte de dos suboficiales del Ejército, durante y con ocasión del servicio, quienes se embriagaron y desatendieron la orden de regresar a la base. La sentencia consideró que los hechos del caso se inscriben dentro del contexto de graves violaciones de los derechos de las mujeres por cuenta de la violencia sexual ejercida en su contra en el contexto del conflicto armado interno.

El alto tribunal determinó que los agresores se valieron de su condición de autoridad, con el fin de cometer tales delitos, los cuales también se produjeron en el contexto del conflicto armado interno, teniendo en cuenta que aquellos fingieron ser miembros de la guerrilla.

Respecto, el fallo reveló que el crimen cometido también buscó el desprestigio del enemigo mediante la imputación falsa del mismo, para lograr una ventaja militar, acción que es típica de la guerra y compromete la responsabilidad estatal, porque usa a la población civil en fines estrictamente relacionados con el conflicto.

\footnotetext{
' El Artículo 1․ de la CBDP define la violencia contra las mujeres como "cualquier acción o conducta, basada en su género, que cause muerte, daño o sufrimiento físico, sexual o psicológico a la mujer, tanto en el ámbito público como en el privado.
} 
Sin embargo, la corporación advirtió que la responsabilidad no solo se derivó de la relación directa del hecho dañino con el servicio y el conflicto, sino también del incumplimiento del Ejército de su deber general de prevención de las violaciones de derechos humanos y la obligación particular de control y disciplina de los agentes a su cargo. El Consejo reprochó la evidente discriminación de género sufrida por la víctima, pues la Policía se negó a recibir y tramitar la denuncia y exigió prueba de la agresión, lo que desconoció el estándar internacional de debida diligencia y vulneró los derechos a la verdad, justicia, reparación y no repetición.

Adicionalmente, el fallo ordenó al Ejército implementar un programa de capacitación de sus miembros que laboran en dicho departamento, donde se difundan los derechos de la mujer y se analice la discriminación contra esta, su situación en el marco del conflicto armado y los lineamientos de prevención, investigación y sanción de este tipo de violencia. Así mismo, exhortó a la Fiscalía General de la Nación y a la Policía, para que eviten las irregularidades en la investigación de esta clase de casos.

\section{EL DERECHO DE LAS MUJERES VÍCTIMAS DE VIOLENCIA SEXUAL A LA IGUALDAD Y EL DEBER CORRELATIVO DE LOS OPERADORES DE LAS NORMAS, INCLUIDOS LOS DEFENSORES, DE ADOPTAR MEDIDAS PARA ELIMINAR Y PREVENIR LA DISCRIMINACIÓN}

La Corte Suprema de Justicia en la sentencia de 23 de septiembre de 2009 dentro del radicado 2350827 (Corte Suprema de Justicia. Proceso N² 23508 de 23 de septiembre de 2009), resaltó la protección internacional de los Derechos Humanos de las mujeres y la obligación de los Estados de garantizar la igualdad entre hombres y mujeres en el goce de todos los derechos. De manera específica, destacó la Convención sobre la Eliminación de todas las Formas de Discriminación contra la Mujer (adoptada por la Asamblea General de la ONU el 18 de diciembre de 1979 y aprobada en nuestro país mediante la Ley 51 de 1981, así como reglamentada por el Decreto 139 de 1990), la cual indicó que: "[...] la discriminación contra la mujer viola los principios de la igualdad de derechos y del respeto de la dignidad humana, que dificulta la participación de la mujer, en las mismas condiciones que el hombre, en la vida política, social, económica y cultural de su país, que constituye un obstáculo para el aumento del bienestar de la sociedad y de la familia y que entorpece el pleno desarrollo de las posibilidades de la mujer para prestar servicio a su país y a la humanidad".

Así mismo, definió la expresión "discriminación contra la mujer" como aquella de la que se desprende "[...] toda distinción, exclusión o restricción basada en el sexo que tenga como objeto o resultado menoscabar o anular el reconocimiento, goce o ejercicio por la mujer, independientemente de su estado civil, sobre la base de la igualdad del hombre, de los derechos humanos y las libertades fundamentales en las esferas política, económica, social, cultural y civil o en cualquier otra esfera". La Corte Suprema de Justicia en dicha sentencia enfatizó también la importancia de la Convención Interamericana para Prevenir, Sancionar y Erradicar la Violencia contra la Mujer (o Convención de Belém do Pará-Brasil), suscrita el 9 de junio de 1994 y aprobada en nuestro país mediante la Ley 248 de 1995, que afirmó que "la violencia contra la mujer es una ofensa a la dignidad humana y una manifestación de las relaciones de poder históricamente desiguales entre hombres y mujeres" y también introdujo como obligación de los Estados que 
suscribieron la Convención la de "adoptar, por todos los medios apropiados y sin dilaciones, políticas orientadas a prevenir, sancionar y erradicar dicha violencia.

En definitiva, esta corporación se ha pronunciado en relación a el derecho a que se haga justicia en el caso concreto, es decir, el derecho a que no haya impunidad y ha manifestado que este derecho incorpora una serie de garantías para las víctimas de los delitos que se derivan de unos correlativos deberes para las autoridades, que pueden sistematizarse así: (i) el deber del Estado de investigar y sancionar adecuadamente a los autores y partícipes de los delitos; (ii) el derecho de las víctimas a un recurso judicial efectivo; (iii) el deber de respetar en todos los juicios las reglas del debido proceso.

\section{CONCLUSIONES}

En términos generales la obligación que tienen los estados de investigar y sancionar graves violaciones de derechos humanos tal como viene dado por la jurisprudencia reiterada de la Corte Interamericana de Derechos Humanos es sin duda un aporte significativo al estado social de derecho porque con ello las altas cortes colombianas en materia de violencia sexual contra mujeres toman como modelo este referente para garantizar la efectividad y la protección necesaria frente a la vulneración de derechos fundamentales tales como el derecho a la vida, el derecho a la integridad física, el derecho a la intimidad y otros inherentes al ser humano.

Por ende en los casos de violencia contra las mujeres la obligación del estado colombiano además de ser iluminado por el enfoque de género este como organismo garante derechos fundamentales debe tener en cuenta los deberes mínimos de debida diligencia en la investigación, juicio y sanción de actos de violencia sexual en contra mujeres, niñas, adolescentes y adultas mayores en el marco del conflicto armado interno y el desplazamiento forzado.

\section{REFERENCIAS BIBLIOGRÁFICAS}

CORTE CONSTITUCIONAL. 2008) “Auto de seguimiento 092".

CORTE CONSTITUCIONAL. (2008) Sentencia T-496 de M.P. Jaime Córdova Triviño; T-843 de 2011, M.P. Jorge Ignacio Pretelt Chaljud; T-234 de 2012, M.P. Gabriel Eduardo Mendoza Martelo.

CORTE INTERAMERICANA DE DERECHOS HUMANOS. (2009) Caso González y otras ("Campo Algodonero") México párr. 258.

CORTE INTERAMERICANA DE DERECHOS hUMANOS. (2010) Caso Rosendo Cantú contra México. Sentencia del 31 de agosto Párr. 189.

CORTE INTERAMERICANA DE DERECHOS HUMANOS. (2010) Caso Fernández Ortega y otros vs. México, Excepciones Preliminares, Fondo, Reparaciones y Costas. Sentencia del 30 de agosto Serie C. No. 215; CIDH. Acceso a la Justicia para las Mujeres Víctimas de Violencia Sexual en Mesoamérica. Ibíd. Párr. 93.

CORTE INTERAMERICANA DE DERECHOS HUMANOS. (2009) Caso Campo Algodonero contra México. Sentencia del 16 de noviembre. Párr. 258. 
CONSEJO DE ESTADO sala de lo contencioso administrativo sección tercera-subsección b consejero ponente: ramiro pazos guerrero Bogotá, D. C, nueve (09) de octubre del dos mil catorce (2014).

CONSEJO DE ESTADO, Sección Tercera, Sentencia 07001233100020020022801 (29033), oct. 9/14, C. P. Ramiro Pazos.

COMITÉ PARA LA ELIMINACIÓN DE LA DISCRIMINACIÓN CONTRA LA MUJER. (Comité CEDAW). Recomendación General No. 19 de 1992.

CONVENCIÓN SOBRE LOS DERECHOS DEL NIÑO Ratificada por Colombia el 19 de enero de 1982.

CONVENCIÓN AMERICANA SOBRE DERECHOS HUMANOS Ratificada por Colombia el 15 de noviembre de 1996.

CONVENCIÓN SOBRE LOS DERECHOS DE LAS PERSONAS CON DISCAPACIDAD Ratificada por Colombia el 10 de mayo de 2011.

DECLARACIÓN Y PLATAFORMA DE ACCIÓN DE BEIJING. Ibíd. Párr. 118; Comisión Interamericana de Derechos Humanos (CIDH). Acceso a la Justicia para Mujeres Víctimas de Violencia en las Américas, OEA/Ser.L/V/II. 20 de enero de 2007. Párr. 67.

PACTO INTERNACIONAL DE LOS DERECHOS CIVILES Y POLÍTICOS Ratificados por Colombia el 29 de octubre de 1969.

PACTO INTERNACIONAL DE LOS DERECHOS ECONÓMICOS, SOCIALES Y CULTURALES Ratificados por Colombia el 29 de octubre de 1969. 